\title{
Selecting a Mode of Way to the Regional Rule of Law
}

\section{At Present China}

\author{
Aiping Li \\ College of Political Science and Law, Northwest Normal University \\ Lanzhou 730070, China \\ Zhejiang Normal University, Jinhua 321004, China \\ Weiyu Ma \\ Zhejiang Normal University, Jinhua 321004, China
}

\begin{abstract}
Regional rule of law itself contains double values of strengthening the theoretical understanding and promoting to solve problems in reality. Its theoretical framework should be made from three perspectives of the regional definition, the functional objectives and cardinal content. In light of the reality in the current China, it is comparatively more reasonable to deeply promote the regional rule of law by continuing the mode of government-promotion road. Of course the conflicts between the unity of the rule of law and regional autonomy, regional rule of law and the unified market construction, official law and unofficial law will appear and needs coordinating.
\end{abstract}

Keywords: Region, Regional rule of law, Mode of government-promotion road

With the rise of regional science and the promotion of the rule by law in China, the regional rule of law has gradually become a brand new theoretical perspective of the topics of governing the country by law. And it is of the conspicuous importance in deeply promoting the legal construction. How to understand its basis of value? How to make the relative theoretical framework? Which mode of road is for the regional rule of law in China? What problems to solve in the course of promoting the mode? This text tries to comb these problems in a systematic way so as to give an initial understanding of the regional rule of law.

\section{The value foundations of the regional rule of law}

Generally speaking, the legal theory has two values, one is for theoretical understanding and the other is for the mechanism of solving the problems in reality. (Chen, Ziqing. 2002.). The research on the value of the regional rule of law should undoubtedly follow this line of thought to give a probe.

\subsection{The value embodiment of the theoretical understanding.}

First, the regional rule of law is one of the topics on legal construction. The rule of law, as an integrative framework of institution, has its own intact system. It has a series of internal structures such as the legislation, judicature, and law enforcement. And it should have level system of broader coverage. From the latter perspective, a law region, a law country and a law community have constituted the three levels of the rule of law. The so-called law region means that a given domain, under the control and governance of a sovereign country, can become a realm with good order by rule of law. (Li, Yubi. 2003.). It is a form demonstrated by rule of law at a certain level and a foundation to realize a law country and law society. It is improper to attach importance to the unity of legal construction while ignore its particularities and differences in various local and regional places or further deny the necessity, reality and pressures of regional construction with rule of law. Professor He Weifang said, "a good social system is actually made up of many small and even trivial mini-systems, just as the billowing Yangtze River of numerous small streams. Without specific rule of law, the grand and ambitious rule of law is only a slogan, a vibration of the air.”(He, Weifang. 2002, p.4)

Secondly, the regional rule of law is the result of the development of regional science. According to the theory of Regionalism, all the activities of human beings need a certain geographical space-region. The growth of economy, politics and culture in any local place or any country has been on with the interaction of other places or countries. And it has been realized or fulfilled in a certain region. At present, with the development of globalization and regionalization, the growth of globalism and regionalism, the regional science has constantly been developing deeply and extensively, resulting in the emergence and boom of regional economy and regional economics. And it gives further competitive 
development to the regional politics, regional administrative science, even the complex administration, and regional public management and other regional theories and practice of multidiscipline, multi-direction, and multi-perspective. Region has become a new perspective of research on the social sciences and humanities, thus contributing to the growth and thriving of different regional sciences (such as, regional economics, regional politics, and regional administrative studies, etc.), all of which aims at exploring the regional harmonious development. In such circumstances, research on regional rule of law will be put on the important agenda of the social sciences. (Wen, Zhengbang. 2005.)

\subsection{The mechanism of solving actual problems.}

The mechanism mainly reflects that the regional rule of law is a rational choice of optimizing the collocation of regional legal resources and promoting the regional development. With the improvement of the standard of the rule of law, the allocation of legal resources has become an indispensable index with which people give to the evaluation of social nature, level of development, social interaction and decision-making. The size of legal standardization and the integrated legal system, the attitudes of the government and the community to law and their credit index have more significance in the economic and social interaction than that of the other resources. A region with complete allocation of legal resources is bound to have much more chances of accessing to effective investment and social interaction than that short of legal resources and with inadequate allocation. A good example of taking good use of legal resources is that the United States promoted the great development in its western region by reforming its law on the real estate. Theory of Adverse Possession was popular with the USA in the 19th century. According to the theory, if someone used the land of others in the identity of the owner and the real owner did not take any measure to give it a stop within the set time, the owner would lose his ownership of the land and the unlawful possessor would take the land ownership. With the further development of the western region, adverse possession became more attractive. In order to make clear the land ownership relations, the law again made a reform in more favor of the adverse possessors. For example, traditionally, the effective period of possession is usually 20 years. But Nevada in 1861 reduced it to five years. (He, Qinghua. 1999. pp.146-148). This law encouraged and induced the influx of new immigrants and the large number of foreign capital investment, and promoted the regional economic development. American experience in the content of concrete provisions and the universality deserves further consideration. But its strategy of developing by law and the idea of effectively establishing legal allocation of resources are of great significance for reference. Furthermore, the regional rule of law itself is a process of optimizing regional allocation of legal resources.

\section{The relevant theoretical framework of regional rule of law}

The theoretical framework of regional rule of law cannot be fulfilled in a day. It needs a continuous and perpetual research of numerous scholars and other people studying law. This text tries to propose some preliminary ideas or strudtures. The narration may not be scientific and reasonable enough. But I really hope to offer a few commonplace remarks by way of introduction so that others may come up with valuable opinions.

\subsection{The definition of region.}

To study the regional rule of law, the first thing is to give a clear definition of region, which is the background and starting-point of constructing regional rule of law. In regional economics, different people may have various understandings about region. Generally speaking, it can be divided into three levels, namely: the region of a country; the world region beyond national boundaries and made up of a few countries; region of parts of several countries. Research on regional rule of law is based on regions within China and followed by defining the scope of a region. According to regional economics, a number of districts and units will be integrated as a region by two criteria: one is the standard of homogeneity and the other functional standard. (Chen, Xiushan. \& Zhang, Keyun. 2003. pp.5-6).

By the standard of homogeneity, we can classify those units or areas with the same or similar characteristics into an integrated region. In this process there are such indicators we can choose as unemployment rate, income, the proportion of heavy industry and so on. As for the standard of function, we can group the units or areas which have close contact one another according to certain indicators into a functional region. These regions are of special high interdependence. The indicators that can be chosen are districts of population flow, product supply area, business and shopping area, etc. The standard is not arbitrary. It is a task on the basis of research programs. And the classification is based on the organic combination of the two standards.

In terms of the standards of the homogeneity, the regional demarcation in the proposition of regional rule of law gives a comprehensive consideration to the similarity of economy, culture and the original legal system, legal systematic construction, and the legal awareness of the social main body among the regions and again combines with the functional objective of regional rule of law serving the legal system modernization. For the benefit of realizing the objective of the rule of law, those areas or units which have similar features or functional values are grouped into a legal region. Meanwhile, given a reasonable consideration of the unity for the rule of law and the regional characteristics, the size of the regions should be appropriate. If the a region is too big, the chance will be comparatively small of embodying and exerting its advantages. If too small, it will be affected greatly by the local features, which resulting in the disharmony 
of the unity of the rule of law. In addition, based on the restrictions on the right as principal by Law of legislation, the regional settings can be as the followings (based on the administrative divisions), a region beyond the provincial boundaries and composed by a few provinces such as the western development region, the eastern developed region, etc., a region based on province, and a region composed by comparatively larger cities or autonomous boroughs within a province or inter-provinces.

\subsection{The value orientation of regional rule of law.}

How to define the value orientation of regional rule of law is a matter of question about both the direction of regional rule of law and the realization of the legal modernization in China. The value orientation of the regional rule of law can be understood from the following two aspects. (Wang, Jianhui. 2002.)

\subsubsection{The unity of the rule of law}

The principle of the rule of law is an rationalized guiding ideology. It is of comprehensive significance of guiding the whole rule of law. And it is an inherent spirit of law which has formed and developed in the process of rule of law. It exists in the conception of rule of law but beyond the law practice. Regional rule of law, as a layer of legal construction in our country, should take the realization of the unity of rule of law as its highest value orientation.

\subsubsection{The innovation of regional legal system.}

The evaluation on whether the existing system is effective on the region is not the pure one on the system itself but the one on the incentive measures, the degrees of protection and the regulations of the regional economy and social development. The effective system must facilitate the growth of the regional economy and social development. Due to the great differences in nature, culture, economy, society and other aspects among the regions, the existing legal system is difficult to meet the needs of the regional economic and social development. A whole set of legal systems must be provided according to the actual situations to suit and promote the rapid development of regional economy and society. These legal systems should be more innovative than the existing ones.

\subsection{The core of the regional rule of law.}

The regional rule of law should be a sound integrated system of internal and external mechanisms. The central task of the research is to explore and study how to establish and better the system of legal norms suitable for the features and actual situations of the regional development. Therefore, the content and structure of the regional legislative system become the core of the regional rule of law and the focus this text is on. Its relevant content can be developed into the following aspects:

\subsubsection{On the legislative principle.}

This is an issue concerning the value orientation of the regional rule of law. Except the general principles that regional legislation should abide by of democracy, science, and procedure, there are some other special principles which must be followed.

First, the principle of unity for the rule of law is demanded by the basic law of the legal construction. It has two layers of meanings. One is to maintain the unity of the entire socialist rule of law. Regional law should be based on the national law and adhere to the non-contravening principle. On one side, it should have no direct conflict against the content of the specific provisions in the higher-level laws. On the other side, it should have no indirect conflict against the basic principles and the spiritual essence of the higher-level laws and the specific legal system defined by the higher-level laws. The other is that the harmony and unity of rule of law among the regions should be kept to be suitable for the local conditions and promote the self-development of the region, and play an active role in facilitating the overall development of every region in China.

Second, the principle of highlighted regional characteristics demands that regional law should reflect the uniqueness of that region. Specifically, first, the regional law should fully reflect the degrees of demand for legal adjustment by economy, politics, culture, customs and the people in that region and the actual situation of adaptability. Second, regional law should have a stronger and concreter target and be able to solve those urgent problems in the region which the Central law does not have relative provisions or is not suitable to solve. It should give a combination to the enacting of regional law and the settlement of the practical problems.

\subsubsection{On the legislative principal.}

In a broad sense, legislation is a comprehensive or complicated task, and it is completed by systems of state organs with legislative right. Likewise, the legislative principal of regional law is the regional state authorities with legislative right and the regional state administrative organs. A legislation mode can be explored of combining the Central special legislation, interregional cooperative legislation and regional independent legislation. The Central special legislation means that the Central legislatures give a prescription as to the overall situation of strategic, structural, macroeconomic and principled issues. The regional cooperative legislation means that more than one regional legislature gives a 
prescription as to interregional, cooperative and the collective issues within the regions. While the regional independent law is made by every regional legislature according to the problems it faces in the development. The Central legislation is basic while the regional legislation is deeper, which is of great significance to allocating the legal resources and bettering the regional legal systems.

\subsubsection{On the legislative content.}

Legislation Law provides that local legislation mainly lies in the following three aspects: first, the legislation for implementation, namely, the implementation of laws and administrative regulations, is stipulated specifically in accordance with the actual situation in the administrative region. The second is the self-determined legislation. That is, legislation is made for the management of regional affairs. The third is antecedent legislation. As to those out of the scope of the national exclusive rights of legislation, the region can make local regulations and laws required before the national legislation. Since the legislation of implementation is relatively fixed, there will be more discussion on the fields and scope of the self-determined legislation and antecedent legislation. Regional legislation has broad and complex range. Generally speaking, it mainly contains the events involved in local economic development, the protection of resources and environment, the labor protection and the protection of rights and interests of special personnel, the adjustment of social relations, the management of public causes, and the regional legislation, law enforcement and judicial affairs, etc.

The theoretical framework of regional rule of law has only laid a theoretical foundation for the rule of law. The following will mainly discuss how to solve the problem of selecting a mode, which is of more realistic value, I suppose.

\section{Selecting a mode of road to the regional rule of law}

There are two types of road modes of modernization of law system in the world. One is the social evolution in the Western developed countries, that is, natural evolution. The other is the government- promotion one in the developing countries. (Wang, Jianhui. 2002.). In light of the current reality in China, the government-promotion mode is a reasonable choice for the construction of our regional rule of law.

\subsection{The macro environment in the process of China's law system determines that the government-promotion mode is more reasonable in a certain phase.}

China is relatively short of traditional legal resources. She is also lack of the conditions of natural evolution of law system. The traditional legal cultural mechanisms bear a strong color of agricultural civilization. The thought of patriarchal clan system has dominated for a long time in history. The society is a typical community ruled by man. And a well-developed civil society is far to reach. Therefore, China does not possess the native resources and institutional mechanisms of the natural evolution in legal system. In this case, if a road is chosen of the natural evolution of the rule of law, it will be long and tortuous because the yielding, evolvement and evolution of the legal resources and the accumulation of public awareness about rule of law cannot be accomplished overnight. Meanwhile, if the state authorities are negative with inaction or just pay attention to the traditional experience, they will meet the hard problems of slow, disorderly, and atavistic spontaneous legal evolution. Opposite to the United Kingdom, France, the United States and other countries, what makes China embark the road of the rule of law, to a large extent, is not from the interior society but within the government. It is pushed or launched by the government.

In addition, the two major tasks that China is facing have demanded the construction of rule of law. First is the in-depth development of China's market economy. It is an economy ruled of law. The rule of law embodying the inherent requirements is the lifeblood of the market economy. China's economic modernization requires speeding up the modernization of the construction, especially, the construction of the non-economy. Laws and rules are needed to maintain the market economy and a new culture is to be reconstructed mainly by law. Second, along with the increasingly strong trend of globalization of the world economy and China's accession to WTO, the economic modernization in the developed Western countries has given tremendous pressure to China. There is no enough time for China to realize her economic modernization. The history of development in the Western developed countries shows that the economic modernization and social rule of law are interdependent. Forced by the demand for the process of building a market economy and the pressure of modernizing the national economy, in the relatively short period of time, the social rule of law must be fulfilled. The government-promotion road can make good use of its later advantage and shorten the time of the rule of law and exert the control power to the extreme degrees in the process to avoid the acute turbulence occurred in the social transitional period. The government-promotion road of rule of law is a proper choice by a country on the basis of national objective situations and the external pressures and challenges to the existence and development of that country. It is a positive response made by a country in front of challenges and pressure. (Jiang, Lishan. 1998.) At the same time, China has powerful political resources in reality. It can provide a chance for practicing the mode of the government-promotion road of rule of law.

In sum, we should say that the government-promotion road of rule of law has its own rational ground in the current phase or in the future. canonical 
3.2 The government-promotion road of rule of law will be more effective from the perspective of promoting the rational allocation of resources and the coordinated development among the regions.

Chinese government owns large and comprehensive system of organizations and strong capacity of control and management. As to the static or dynamic resource of the region, there is every chance for it to give a full control. Through the government, the existing legal resources can be fully used to give a wide range of adjustments to the various economic relations and economic activities. By means of law, various incentive mechanisms of interests and right protection can be established to fully mobilize and bring into play the enthusiasm, initiative and creativity of the market principal, thus giving effective preparations of the various resources.

At the same time, there exist differences and imbalances in development of different regions, which is prevalent in each area and country. The countries with developed market economy have succeeded in applying proper regional policies to harmonize the development of different regions through the government. In terms of the reality in our country, the coordinated development of regional economy can be achieved through the adjustment of rule of law. China is a country with unified rule of law, which requires harmonized legal principles and legal institutions. However, the regional economic development may require more objective, more favorable environment or much more ascendant small platform to adjust and regulate the special cases or problems in that region, for example, how to reduce the impact of administrative divisions, how to achieve the reasonable adjustment of the regional industrial layout, and so on. All these should be made and arranged by local legislations or local laws before the whole country gives a unified regional economic cooperation law.

In all, it can be seen that at present and in the near future, to develop regional rule of law by adopting the mode of government-promotion road is more reasonable. But it will not be smooth and there will be a series of problems or even conflicts for us to give a solution.

\section{The obstacles of the government-promotion mode of regional rule of law and its countermeasures.}

Undoubtedly, a series of problems and potential dangers that may exist in the construction of rule of law promoted by the government will be found in the regional rule of law mainly driven by the government. I will not give further explanations about these problems for many scholars have made in-depth studies on them and given the corresponding countermeasures. I will concentrate on the problems and ways of solution because of the regional uniqueness that may appear in the government-promotion mode of regional rule of law.

4.1 The conflicts and adjustment of the unity of regional rule of law and the regional self-determination in construction of the regional rule of law.

It is inevitable that the conflicts exist between the unity of the rule of law and regional self-determination. They are between the Central and the local legislation, or within the local legislation in the same region.

4.1.1 The harmonization of relations in the Central legislation and the regional legislation.

Adjusting the relations of the Central and regional legislation should start from the Central and the local perspectives. It is the most important issue to make clear the divisiory scope of right between the Central and regional legislation in the Central angle. The central and regional relations include the mandate and restriction, only through which can the regional legislation be on the good way to scientific development. The mandate shows that regional authorities are recognized legally to have the rights to enact, amend and repeal regional law. One of the restrictions is that, in terms of position, the Central legislation has dominant position while the regional is secondary. The other restriction is that, as far as content is concerned, the Central legislation is of importance with universal principles, while the regional legislation is localized, targeted and complementary. (Tang, Wei. \& Bi, Kezhi. 2002. p.140).

From the perspective of regional legislation, some points need making clear. First, the regional legislation can not overstep their popedom. The regional legislation cannot set foot in the exclusive legislative purview of the National People's Congress and its Standing Committee unless authorized by the state. Except that what is prescribed in the article 8 of Legislative Law, as to the other matters that the state have not developed into national laws or administrative regulations yet, the local authorities can formulate local laws and regulations according to the actual need. Once the national law or administrative rules become effective, the relevant local laws and regulations that are in conflict with them must be promptly amended or abolished. Secondly, as for the legislative programs that the state have recently introduced, the regional council should not be anxious to make laws. Thirdly, if the state authorizes the local council to develop the measures of enforcement, the local council should take the local practice into consideration to decide whether the measures of enforcement can be enacted.

4.1.2 The coordination of local legislation within the same region.

In a region of a province, when the province (or directly administered municipality) makes or adjusts the legislative plans, the provincial people's congress and its standing committee and the National People's Congress and its Standing Committee of the larger city in the province should pay attention to the joint and harmony of the legislative programs in 
order to avoid the repetition and even conflicts and enable the two layers of legislative activities to operate orderly and harmoniously as an organic whole. Special region should fix the eyeballs on the appropriate coordination with the autonomous regulations and separate regulations in the autonomous eparchies or counties within the region. Attention should be also paid to the harmony of the regional laws and regulations with the governmental rules, and to planning as whole the relationship between legislation by the National People's Congress and the administrative rules and regulations by the government.

\subsection{The conflicts and coordination of regional rule of law and the construction of the unified market.}

In the process of promoting the regional rule of law, there will appear the conflicts of rule of law among the regions due to the inter-regional differences of economy, culture and customs. The conflicts need to be well coordinated because they deviate from the demand of the unified market system in China to some degrees. In the United States, the interstate agreement is the most important mechanism of regional rule of law to achieve interstate cooperation and settle the interstate disputes.

Accordingly, in Chinese mode of coordination in the regional rule of law, regional cooperation and administrative agreement should be the most important mechanism of coordination.

Regional collaboration has essentially a gradual process. And its rule is the legal system which has universal control and all members of the regional economic community should abide by. From the angle of the legal effects, the legal system of community of regional collaboration is between national legal system and local laws and regulations. Jilin, Liaoning and Heilongjiang arrived at a framework agreement of legislative cooperation on July 3, 2006 and jointly established the fields of collaboration, including the encouragement and protection of non-public economic development, the building of the community of integrity, dealing with unexpected public events, standardizing the supervision of law enforcement and developing the management of the national institutions and organizations and so on. It is a good innovation of regional collaboration. The administrative agreement, displaying the joint meeting system of the regional governments, similar to the interstate agreements in the United States and the administrative agreement in Spanish Public Administration and the Common Administrative Procedure Law, is a legal mechanism to achieve equality and cooperation among governments. For example, the Yangtze River Delta economic cooperation region has the Statute of City Economic Coordination Union in the Yangtze River Delta. In November 2004, the Cooperation Agreement of the Yangtze River Delta Cities was signed in Shanghai. The local governments in pan-Pearl River Delta region are the first to reach the Framework Agreement of Regional Cooperation in Pan-Pearl River Delta, a general principle. And then various concrete and specialized administrative agreements have been reached by the respective functional departments.

\subsection{The coordination of the relations between the official and unofficial laws.}

Masaji Chiba's first tier of dichotomy about law is official and unofficial. (Masaji, Chiba. 1997. p.190). He believes that the unofficial law is widespread in the civilian population, and is obeyed by the people in daily life. It has given great influences on the enforcement and functions of the national law. Thus, it is important to make clear their relations. In the researches about the plural theories of laws similar to the classification of the official and unofficial laws, more Chinese scholars incline to use the terms of national law and fork law. The reason why it is called folk law is that it is a spontaneous system of rule outside of the national law thought its formation and development cannot avoid the influence of the national formal legal system. It is the externalization of the people's will rather than the state will. I would like to borrow the conception of local knowledge by Goulds to interpret this. "Law is the common knowledge of a local place. Here the local place does not only refer to space, time, class and the various issues, but also to the accent. That is to say, the local awareness of what has happened should be linked to the local imagination of the would-be incidents". (Goulds, 1994. pp.73-171). The folk law is a kind of regulation that a certain community of people has accumulated and formed in a long living and working time. The national law is universal and uniform while the folk law is special and decentralized with a very strong local accent, which results in the conflicts, more acute and difficult to settle within the same region. And it has become a major problem that regional rule of law is facing.

To harmonize the contradictions, in the legislative process, first of all, the national law must actively communicate with the folk law, fully absorb the useful and constantly get self-improvement. It is the mission for national law. Otherwise, the national law will not be able to operate effectively and evading the law will become a universal phenomenon. (Su, Li. 1996. pp.59-73). The main means of positive interaction in Japan is that the national law can absorb the nonofficial law in a certain way by examination, selection and re-interpretation. The unofficial law has three ways to the official law. It can be regarded as "practices" or "common law" and recognized by enacted laws, or it becomes applicable of free judgment approved by the legal authorities, or it can be indirectly arrived at through the people's freedom of choice (the right $\mathrm{s}$ based on the Constitutional personal liberty). (Masaji, Chiba. 1997. p.120). It has great significance for reference in the process of regional rule of law. At the same time in the course of positive communication and interaction, several guiding principles should be followed. On one side, the authority of official law should be stressed to safeguard the unity of the state legal system. On the other side, the social relations with strong local accent and folk colors can be dealt with by the folk law while the official law should have necessary tolerance and patience. A good and 
positive interaction between the official and folk laws through such effective communication is not only conducive to the realization of the regional rule of law but also to the cultivation of law resources in the civilian population and to lay a foundation for the rational transition of realizing the rule of law from the government-promotion mode to the natural evolution one.

\section{References}

Chen, Xiushan. \& Zhang, Keyun. (2003). Theory of Regional Economy. The Commercial Press.

Chen, ZiQiang. (2002). On Groundless Bonds and Contracts. China University of Politics and Law Press.

Goulds. (1994). Local common knowledge: comparative perspective of facts and the law. Trans. Zhenglai, Deng. Cultural Interpretation of Laws by Zhiping, Liang. Sanlian Bookstore.

Gong, Pixiang. (1999). The Theoretical Logic of the Legal System Modernization. China University of Politics and Law Press.

He, Qinhua. (1999). History of the Law Development in the United States. Shanghai People's Publishing House

He, Weifang. (2002). Specific Rule of Law. The Law Press.

Jiang, Lishan. (1998). Research on road of Chinese modernization of the rule of law (1). China Legal Science.

Li, Yubi. (2003). The significance of the western regional rule of law-Also on the regional rule of law, countries and communities by law. National People's Congress System Studies. Issue 2.

Masaji, Chiba. (1997) Legal Pluralism-form Japanese Law to the General Legal Theory. China University of Politics and Law Press.

$\mathrm{Su}$, Li. (1996). The Rule of Law and the Local Resources. China University of Politics and Law Press.

Tang, Wei. \& Bi, Guangzhi. (2002). Conceiving the democratic and scientific local legislation. Beijing University Publishing House.

Wen, Zhengbang. (2005). Research should be made on the regional rule of law-from the perspective of the western development. Law Studies.

Xie, Hui. (1998). Reflection over reconstructing the value and making a canonical choice of Chinese modernization of legal system. Shandong People's Publishing House.

Wang, Jianhui. (2002) Research on the value orientation of the local legislation in China. Modern Law Science. 